\title{
Concentration of Elements in Food: How Can It Reflect Impact of Environmental and Other Influencing Factors?
}

\author{
Zane Vincevica-Gaile ${ }^{1}$, Maris Klavins ${ }^{2},{ }^{1-2}$ University of Latvia
}

\begin{abstract}
Element content of food is variable and can be influenced by different factors. The aim of the present study was to discover the linkage between macro- and microelement concentrations in food produced in Latvia, and possible impacts of environmental factors. More than $\mathbf{3 0 0}$ fresh food samples such as eggs, cottage cheese, honey, root vegetables, apple juice, apple wine were collected in the time period from 2009 to 2011. Samples were mineralised or analysed directly by appropriate method of quantitative analysis: atomic absorption spectrometry, inductively coupled plasma mass spectrometry or total reflection $\mathrm{X}$-ray fluorescence spectrometry. Statistical analysis of data revealed that food elemental content can be influenced by sitespecific factors such as geographical origin, seasonality, environmental pollution.
\end{abstract}

Keywords - Environmental factors, element transfer, food, quantitative analysis, macroelements, microelements.

\section{INTRODUCTION}

Human health, welfare and life quality to a great extent is dependent on the quality of food consumed daily. The influence of the surrounding environment should also be taken into account. Macro- and microelements naturally occur in all phases of environmental systems: lithosphere, hydrosphere and atmosphere from where they are transferred into the biosphere, but the ambient element concentrations and forms of element speciation are very variable and may influence biology and physiology of plants, animals and humans [1]. Although element circulation in ecosystems is a constant process among the main constituents of the biosphere (soil, water and air), vegetation is the primary recipient of macroand microelements from the environment, taking up elements via roots and foliage [2].

Chemical composition of soil, water and air is not constant and varies widely due to various global and regional factors, e.g., climate zone and seasonal conditions, geochemical background, hydrological cycles, pollution rate. It is not possible to estimate unitary environmental backgrounds of elements in any environmental system on Earth, but by estimating regional environmental backgrounds of macro- and microelements provides indication of potential risks for populations in selected areas [3].

Place specific ambient environmental factors with interconnection of anthropogenic influences may affect element content in food. For example, element concentrations in soil can be reflected in the elemental composition of plants that are consumed by animals or are used as human food, thus resulting in element transfer into the food chain that may affect health and longevity [4]. Food contamination with toxic elements (e.g., As, $\mathrm{Cd}, \mathrm{Hg}, \mathrm{Pb}$ ) and potentially toxic elements (e.g., $\mathrm{Al}, \mathrm{Cr}, \mathrm{Cu}, \mathrm{Ni}, \mathrm{Sn}, \mathrm{Zn}$ ) may occur and consumption of contaminated food can result in chronic or acute adverse effects for consumers.

Soil can be assessed as the major source of elements. The main sources of soil contamination with trace inorganic pollutants are industry, mining and smelting, brick, pipe, cement, ceramic, glass manufacture, chemical industry, power generation, combustion of fossil fuels and municipal waste, nuclear reactions, agricultural activities, sewage sludge and manure applications, use of mineral fertilizers and pesticides, transport and urban pollution. It has been estimated that the most hazardous elements for the biosphere are Ag, $\mathrm{Au}, \mathrm{Cd}, \mathrm{Cr}$, $\mathrm{Cu}, \mathrm{Hg}, \mathrm{Pb}, \mathrm{Sb}, \mathrm{Tl}$ and $\mathrm{Zn}$, while the least hazardous elements are considered $\mathrm{Ga}$, La, Nb, Sr, Ta and Zr [5].

Regional assessment of food element content in connection with estimation of environmental and anthropogenic impacts is an issue of great importance. Information on macro- and microelement content in locally produced food may also be an indicator of regional environmental element background. Quantitative detection of element concentrations is an indispensable tool for risk assessment analysis that can be associated with possible excessive intakes of elements and may lead to toxic adverse effects in the human body or, conversely, can be connected with possible insufficiency of element intake that may cause deficiency of certain elements in the human body [6].

The aim of the present study was to discover the linkage between macro- and microelement concentrations in food produced in Latvia, a country in northern Europe, and possible impacts of environmental factors.

\section{MATERIALS AND METHODS}

\section{A. Selection of samples, sampling and storage}

The selection of food samples within this study was based on the element transfer route from the environment into the food chain. Various food samples were collected: a) food of animal origin derived by or without processing (e.g., cottage cheese, eggs); b) food that is consumed without processing such as bee products (e.g., honey); c) food of plant origin, such as locally grown vegetables (e.g., carrots, onions); d) locally produced beverages (e.g., apple juice, apple wine). 
Fresh food samples were collected over the territory of Latvia in the time period from 2009 to 2011. Food samples were purchased in markets or obtained directly from producers or households.

Some food samples were analysed fresh immediately after collection (e.g., beverages), however, most of samples were prepared and stored in appropriate conditions packed in disposable plastic bags or vessels until analyses. For example, root vegetables were washed, peeled, crushed, oven-dried and the powdered samples were stored in a dark, dry place, but egg samples (separately egg albumen and egg yolk) and cottage cheese samples were stored frozen at $-20^{\circ} \mathrm{C}$. Only ceramic, glass and polypropylene tools and vessels were used to avoid sample contamination with traces of metals.

In total more than 300 food samples of local origin from Latvia were quantitatively analysed within the present study. For comparison, some imported food samples were purchased and analyzed.

\section{B. Sample pre-treatment}

Sample pretreatment was chosen according to the food sample specifics, but mostly wet mineralization was applied. Mineralization is necessary not only for cleavage of organic matrix of biological samples, but it also helps to prevent analytical techniques from unwanted residues that can settle on the burner head and in the spray chamber, and thus can affect spectral interferences resulting in inaccuracy of measurements [e.g., 7]. While total reflection X-ray (TXRF) spectrometry allows direct sample analysis, detection of elements in biological or environmental samples by atomic absorption spectrometry (AAS) or inductively coupled plasma mass spectrometry (ICP-MS) requires more complicated sample pre-treatment. Sample pre-treatment can be realized by several methods, such as dry ashing, wet ashing, wet digestion forced by heat, microwave or ultrasound influence [8].

Wet mineralisation applied for food samples within this study was done as it is widely described in literature [e.g., 9]: 1) certain amount $(0.5-3.0 \mathrm{~g})$ of the sample was precisely weighed on analytical balance in a glass beaker; 2) analytically pure reagents (conc. $\mathrm{H}_{2} \mathrm{O}_{2}$ and conc. $\mathrm{HNO}_{3}$ ) were added and solutions were held overnight; 3 ) sample dissolution was accelerated by heating it at $160^{\circ} \mathrm{C}$ until complete digestion; 4) solution was cooled, then quantitatively transferred into a polypropylene test tube and filled up to $50 \mathrm{ml}$ with ultra pure deionised water. Each sample was prepared in triplicate and in the same manner blank solutions were made. In the same manner certified reference samples apple powder NCS ZC73017 (GSB-10)-Apple ("LGC Promochem”) and lichen powder IAEA-336 (International Atomic Energy Agency) were prepared for analysis.

Some samples, such as apple juice and apple wine were analysed directly without any pre-treatment. For direct sample analysis by TXRF as reference sample red wine PT Red wine - Chilian ("LGC Standards") was used. In case of sample analysis by TXRF spectrometry gallium solution $(0.01 \mathrm{~g} / \mathrm{l})$ was added as internal standard immediately prior to the analytical procedure.

\section{Applied analytical methods}

There were three quantitative analysis methodologies used for food sample analysis within the present study: a) atomic absorption spectrometry (AAS); b) inductively coupled plasma mass spectrometry (ICP-MS); c) total reflection X-ray fluorescence spectrometry.

AAS was applied mainly for macroelement (Ca, Fe, K, Mg, $\mathrm{Na}$ ) quantification by exploiting a “AAnalyst 200" (PerkinElmer) spectrometer. ICP-MS is a more sensitive method and it was applied for microelement (Ag, As, Ba, Cd, $\mathrm{Ce}, \mathrm{Co}, \mathrm{Cr}, \mathrm{La}, \mathrm{Ni}, \mathrm{Pb}, \mathrm{Rb}, \mathrm{Se}, \mathrm{Sr}, \mathrm{V}$ ) quantification by using "ELAN DRC-e” (PerkinElmer) ICP-MS apparatus.

Total reflection X-ray spectrometry is a relatively simple, cheap, non-destructive and time-saving method for element quantification due to the possibility to analyse environmental and biological samples directly without complicated digestion procedure [10]. Prior to analysis, the organic material is to be mixed with an internal standard, and the method allows fast and accurate $(\sim 15 \%)$ analysis of all microelements heavier than aluminium [11]. The range of elements ( $\mathrm{Ba}, \mathrm{Ca}, \mathrm{Cu} \mathrm{Fe}$, $\mathrm{K}, \mathrm{Mn}, \mathrm{Ni}, \mathrm{P}, \mathrm{Pb}, \mathrm{Rb}, \mathrm{S}, \mathrm{Se}, \mathrm{Sr}, \mathrm{V}$ and $\mathrm{Zn}$ ) was quantitatively detected by using TXRF spectrometer "PicoTAX" (Rontec $\mathrm{GmbH})$. TXRF was used for analysis of fresh beverage samples and also for analysis of egg samples.

\section{Approach of statistical analysis}

Statistical analysis was performed by using MS Excel data analysis tools. For every data set the main statistical parameters were calculated (standard deviation, mean, median etc.). For comparison of data sets, Pearson correlation was applied or Student's tests were performed (t-Test: Two-Sample Assuming Equal Variance; t-Test: Two Sample Assuming Unequal Variances), as well as ANOVA test was performed in case of necessity.

\section{RESULTS AND DISCUSSION}

\section{A. Impact of origin}

As the origin of food samples was different (detected at the time of sample collection), it was possible to detect distinctions among selected sample subgroups. Geographical dissemination of elements in honey [12] and impact of botanical origin on potentially toxic element concentration of honey [13] can be mentioned as examples.

Considering geographical origin of honey samples, sample subgroups were set based on the regional geological information of Latvia such as parent soil grading composition and soil type. Furthermore, the selected regions were differed by the intensity of agriculture, traffic, industrial activities and cross-border impact intensity. Comparison of macro- and microelement concentrations of honey in between selected subgroups revealed that only for $\mathrm{Cu}, \mathrm{Fe}, \mathrm{Mg}$ and $\mathrm{V}$ were there no detectable substantial differences. Such elements as Mo, $\mathrm{Zn}, \mathrm{Pb}$ and $\mathrm{Ca}$ were detected in higher concentrations in honey samples collected in the area with clay, peat or sandy loam (podsol and pseudoglay) as parent soil material and intensive cross-border impact of possible pollutants by airflows. However, detected interconnections within the element 
concentrations of honey were estimated as slightly affected by geochemical background. More influence on element concentrations of honey can be attributed to anthropogenic activities, such as traffic agriculture and application of agrochemicals [12].

In case of impact of botanical origin of honey it was also possible to evaluate influence of pollution, e.g., in honey from linden blossoms some elements $(\mathrm{Pb}, \mathrm{As})$ were detected in higher levels. It is known that linden trees are widely grown in urban areas or near roads in Latvia which can be potential sources of element contamination with microelements. Agricultural activities and the use of agrochemicals and fertilizers can also become a source of elements such as $\mathrm{Cd}$, $\mathrm{Co}, \mathrm{Cu}$ for some types of samples such as honey from rape and buckwheat honey [13].

\section{B. Impact of seasonality}

Impact of seasonality on element concentrations in food within the present study can be reflected by analysis of seasonally collected cottage cheese samples and egg samples derived from household farms with known poultry housing conditions.

Concentrations of detected major elements (Ca, K, Mg, Na) in cottage cheese samples collected in the winter season was obviously higher than in samples from spring/summer seasons (Fig. 1). This can be linked to seasonal animal feeding and breeding conditions. During the winter dairy animals are fed by feed supplemented with extra mineral content that has possibly reflected on the elemental content of dairy products.

Impact of seasonality was determined also for concentrations of microelements in cottage cheese. Results of
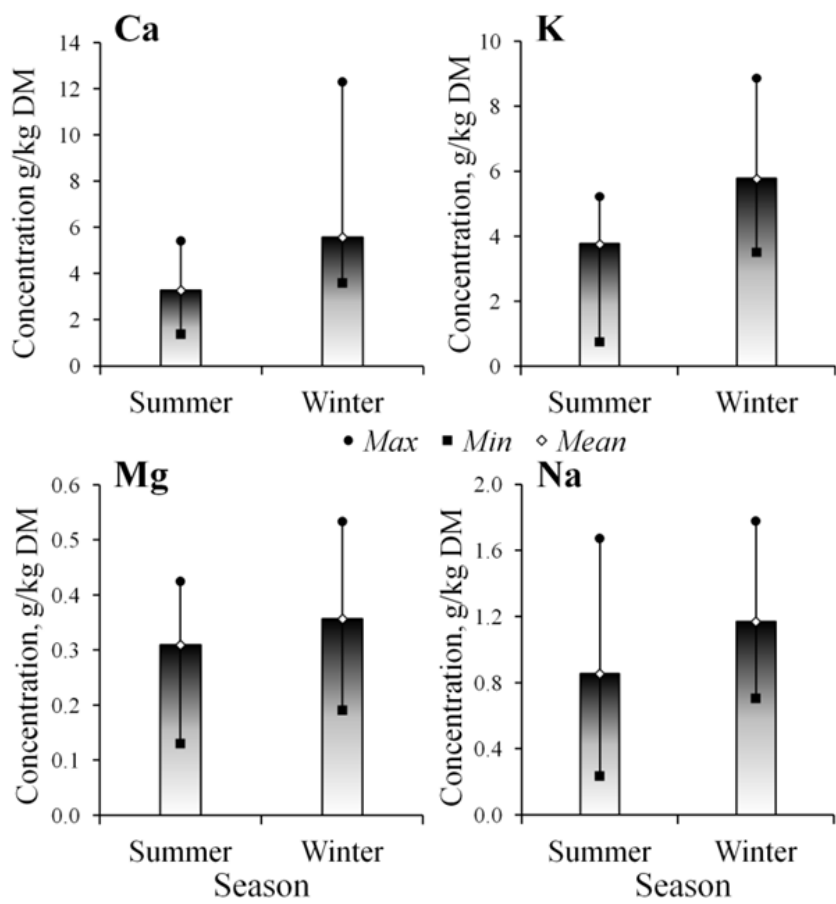

Fig. 1. Seasonal distinctions of macroelement concentrations of cottage cheese samples from Latvia. analyses revealed that potentially toxic elements and environmental pollutants such as $\mathrm{Pb}$ and $\mathrm{Ni}$ prevailed in the cottage cheese samples derived in the spring/summer seasons [14].

In case of egg analysis, the highest concentrations of $\mathrm{Fe}, \mathrm{Zn}$ and $\mathrm{Cu}$ in egg yolk samples were detected in the samples collected in the summer season. Ca and $\mathrm{K}$ concentrations in egg albumen and yolk were higher in samples from the winter season. $\mathrm{Pb}$ was not detected in any egg sample from the autumn and winter seasons, thus reflecting a diminished outdoor pollution impact (Tab. 1). Poultry breeding in outdoor conditions in the summer and spring seasons can lead to the contamination of poultry products with potential environmental contaminants via the food chain from soil, rainwater, air dust.

Concentration of Se in samples from the winter season was detectable in both, egg albumen and yolk, reflecting influence of complex mineral feed on egg elemental content, as the soils of the territory of Latvia are Se deficient [15].

\section{Estimation of other impact factors}

Within the present study through the analysis of root vegetables of different species it was possible to detect species related peculiarities. For example, regarding detected concentrations of several elements it was obvious that carrots can more intensively take up potentially toxic elements than onions (Fig. 2). That can be associated with botanical specifics of a species such as root system, foliage and growth time before harvesting.

TABLE I

SEASONAL DisTinctions OF MACRO- AND MiCROELEMENT CONCENTRATIONS IN EGG (ALBUMEN/YOLK) SAMPLES FROM LATVIA

\begin{tabular}{|c|c|c|c|c|}
\hline \multirow{2}{*}{ Element } & \multicolumn{4}{|c|}{ Sampling season } \\
\cline { 2 - 5 } & Spring & Summer & Autumn & Winter \\
\hline \multicolumn{5}{|c|}{ Macroelements, g/kg } \\
\hline $\mathrm{Ca}$ & $0.04 / 0.86$ & $0.03 / 0.86$ & $0.04 / 0.74$ & $0.08 / 0.88$ \\
$\mathrm{~K}$ & $1.67 / 1.20$ & $1.18 / 0.95$ & $1.08 / 1.11$ & $1.71 / 2.10$ \\
$\mathrm{P}$ & $0.29 / 8.48$ & $0.28 / 8.41$ & $0.20 / 8.11$ & $0.27 / 7.35$ \\
$\mathrm{~S}$ & $5.58 / 4.29$ & $5.62 / 3.70$ & $5.05 / 4.35$ & $4.92 / 4.23$ \\
\hline \multicolumn{5}{|l}{} \\
Microelements, mg/kg & $0.27 / \mathrm{n}$. & $0.25 / \mathrm{n}$. & $\mathrm{n} . / \mathrm{n}$. & $0.45 / \mathrm{n}$. \\
$\mathrm{Cr}$ & $0.13 / 1.39$ & $0.25 / 1.25$ & $0.27 / 1.08$ & $0.12 / 1.06$ \\
$\mathrm{Cu}$ & $0.82 / 37.57$ & $1.40 / 42.57$ & $8.46 / 35.78$ & $4.58 / 35.13$ \\
$\mathrm{Fe}$ & $0.30 / 0.33$ & $0.28 / 0.35$ & $0.23 / 0.09$ & $0.03 / 0.18$ \\
$\mathrm{Mn}$ & $0.10 / 0.13$ & $0.20 / \mathrm{n}$. & $0.05 / \mathrm{n}$. & $0.02 / \mathrm{n}$. \\
$\mathrm{Nb}$ & $0.10 / 0.03$ & $0.17 / 0.13$ & $\mathrm{n} . / \mathrm{n}$. & $\mathrm{n} . / \mathrm{n}$. \\
$\mathrm{Se}$ & $\mathrm{n} . / 0.12$ & $\mathrm{n} . / 0.13$ & $\mathrm{n} . / 0.08$ & $0.02 / 0.13$ \\
$\mathrm{Zn}$ & $0.64 / 27.62$ & $0.43 / 30.30$ & $0.52 / 25.26$ & $0.08 / 24.5$ \\
\hline
\end{tabular}

$*_{n .}-$ not detected 

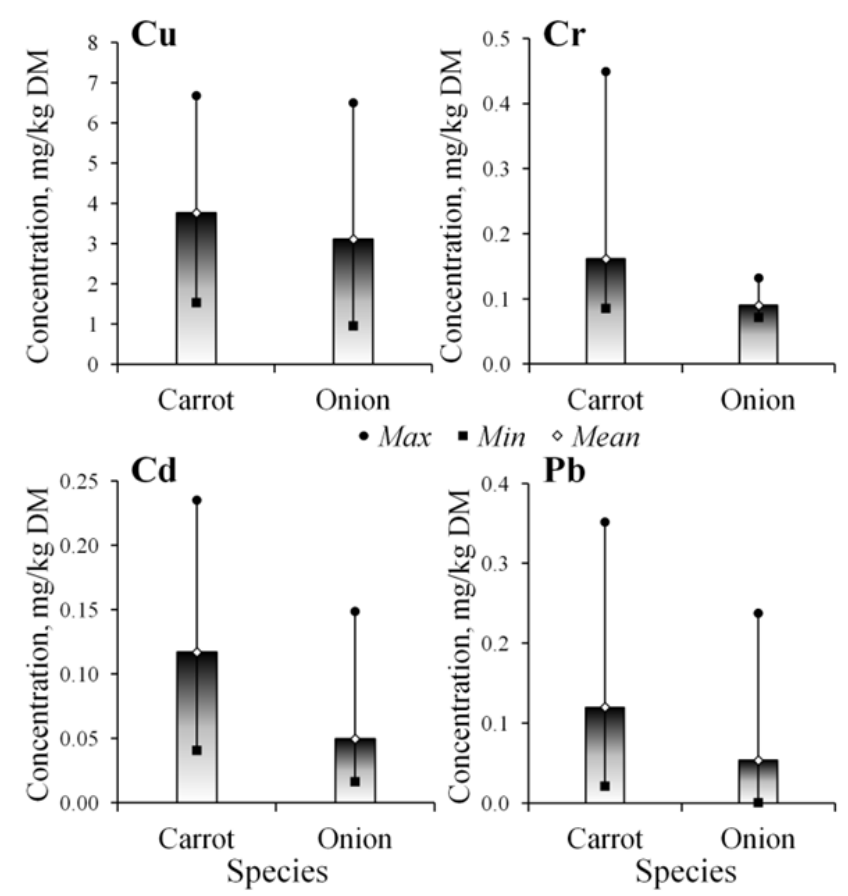

Fig. 2. Comparison of some potentially toxic element concentrations between species of root vegetables carrots and onions from Latvia.

TABLE II

COMPARISON OF MACRO- AND MICROELEMENT CONCENTRATIONS IN BEVERAGE SAMPLES (MIN-MAX (MEAN)) FROM LATVIA

\begin{tabular}{|c|c|c|}
\hline \multirow{2}{*}{ Element } & \multicolumn{2}{|c|}{ Sample of beverage } \\
\cline { 2 - 3 } & Apple juice & Apple wine \\
\hline \multicolumn{2}{|c|}{ Macroelements, mg/L } \\
\hline $\mathrm{Ca}$ & $29.01-69.84(43.86)$ & $14.02-82.61(40.84)$ \\
$\mathrm{K}$ & $1052.81-1390.14(1189.18)$ & $399.65-1195.15(833.25)$ \\
$\mathrm{Mg}$ & $38.45-51.29(42.87)$ & $18.63-84.35(50.73)$ \\
$\mathrm{Na}$ & $1.16-24.98(5.47)$ & $6.70-26.09(14.63)$ \\
\hline Microelements, mg/L & $0.02-0.04(0.03)$ \\
\hline $\mathrm{Cu}$ & $0.03-0.13(0.07)$ & $0.30-1.72(0.91)$ \\
$\mathrm{Fe}$ & $0.31-2.00(0.95)$ & $0.08-0.30(0.21)$ \\
$\mathrm{Mn}$ & $0.10-0.27(0.23)$ & $0.01-0.09(0.03)$ \\
$\mathrm{Ni}$ & $<0.004$ & $0.07-0.35(0.17)$ \\
$\mathrm{Zn}$ & $0.09-0.51(0.19)$ &
\end{tabular}

Analysis of beverages such as apple juice and apple wine, revealed differences in element content connected with food processing, i.e., the process of fermentation. The quantitative results showed that some elements (e.g., Ca, K, Cu) are detectable in apple juice in higher levels than in apple wine. However, for several elements distinctions were not significantly considerable. $\mathrm{Ni}$ is the element that was not detected in juice, but was found in wine, thus making the suggestion of possible contamination from metal vessels (Tab. 2).

By analysing root vegetables it was also possible to determine the impact of agricultural conditions on element concentrations, i.e., distinctions were detected between sample subgroups grown in allotment gardens (at small scale households) and farmlands [16]. According to the comparison of variances by Fisher's criteria and the results of the performed appropriate t-tests for samples of onion bulbs, only the concentration of $\mathrm{Na}$ was significantly different within the selected subgroups reflecting that $\mathrm{Na}$ concentration in onions from farmlands is significantly higher. That can be associated with possible farmland contamination with Na salts from use of fertilizers and agrochemicals.

Statistical analysis of macroelement concentrations in carrot roots revealed significant differences between subgroups for two elements: concentrations of $\mathrm{K}$ and $\mathrm{Mg}$ in the subgroup of samples grown in allotment gardens was significantly higher than in the subgroup of carrot samples grown in farmlands. Overall, a comparison of selected subgroups revealed that amounts of several elements (Cd, Co, Na, Ni, Se, $\mathrm{Sr}$ ) were significantly higher in the subgroup of onion samples grown in farmlands.

For carrots, significantly higher amounts of some elements ( $\mathrm{K}, \mathrm{Mg}, \mathrm{Mn} \mathrm{Rb}, \mathrm{Zn}$ ) were detected in samples from allotment gardens. Such differences may occur due to the impact of natural geochemical background or from the use of soil fertilizers that can influence concentrations of macroelements and use of pesticides regarding some microelements [16].

\section{CONCLUSIONS}

The present study showed how variable the range of factors are that have to be taken into account within the estimation of transfer of elements in food. Statistical analysis of quantitative data revealed that food elemental concentrations can be influenced by site-specific factors such as geographical origin, seasonality, environmental pollution, applied agricultural praxis and also food processing. It was estimated that impact of environmental factors is important and it can affect food quality and consumer safety.

\section{ACKNOWLEDGEMENTS}

This work has been supported by the European Social Fund within the project "Support for Doctoral Studies at University of Latvia”.

\section{REFERENCES}

1. Bowman, C. A., Bobrowsky, P. T., Selinus, O. Medical Geology: New Relevance in the Earth Sciences. Episodes, 2003, vol. 24, N 6, p. 270278.

2. Voutsa, D., Grimanis, A., Samara, C. Trace elements in vegetables grown in an industrial area in relation to soil and air particulate matter. Environmental Pollution, Vol.94, No.3, 1996, p. 325-335.

3. Selinus, O. (ed.-in-chief) Essentials of Medical Geology. Elsevier Academic Press, 2005, p. 18-35, 832 p.

4. Fraga, C. G. Relevance, Essentiality and Toxicity of Trace Elements in Human Health. Molecular Aspects of Medicine, 2005, vol. 26, N 4-5, p. 235-244.

5. Kabata-Pendias, A., Mukherjee, A. B. Trace Elements from Soil to Human. Springer-Verlag, 2007, 550 p.

6. Goldhaber, S. B. Trace Element Risk Assessment: Essentiality vs. Toxicity. Regulatory Toxicology \& Pharmacology, 2003, vol. 38, N 2, p. 232-242.

7. Soceanu, A., Dobrinas, S., Popescu, V., et al. Comparative Study of Some Essential Elements in Different Types of Vegetables and Fruits. Environmental Engineering \& Management Journal, 2007, vol. 6, N 6, p. 593-596. 
8. Alvarez, J., Marco, L. M., Arroyo, J., et al. Determination of Calcium, Potassium, Manganese, Iron, Copper and Zinc Levels in Representative Samples of Two Onion Cultivars Using Total Reflection X-Ray Fluorescence and Ultrasound Extraction Procedure. Spectrochimica Acta, Part B: Atomic Spectroscopy, 2003, vol. 58, N 12, p. 2183-2189.

9. Kilic, Z., Acar, O., Ulasan, M., et al. Determination of Lead, Copper, Zinc, Magnesium, Calcium and Iron in Fresh Eggs by Atomic Absorption Spectrometry. Food Chemistry, 2002, vol. 76, N 1, p. 107116.

10. Hoefler, H., Streli, C., Wobrauschek, P., Ovari, M., et al. Analysis of Low Z Elements in Various Environmental Samples with Total Reflection X-Ray Fluorescence (TXRF) Spectrometry. Spectrochimica Acta Part B: Atomic Spectroscopy, 2006, vol. 61, N 10-11, p. 11351140.

11. Kubala-Kukus, A., Braziewicz, J., Pajek, M. Total Reflection X-Ray Fluorescence Studies of Trace Elements in Biomedical Samples. Spectrochimica Acta Part B: Atomic Spectroscopy, 2004, vol. 59, N 8 , p. 1283-1289.

12. Vincevica-Gaile, Z., Klavins, M., Rudovica, V., et al. Geographical Dissemination of Trace and Major Elements in Honey. In: Brebbia, C. A. (ed.) Sustainability Today, WIT Press, 2012, p. 211-220.

13. Vincevica-Gaile, Z., Klavins, M., Rudovica, V., et al. Potentially Toxic Metals in Honey from Latvia: Is There Connection with Botanical Origin? In: Ramos, R. A. R., Straupe, I., Panagopoulos, T. (eds.) Recent Researches in Environment, Energy Systems \& Sustainability, WSEAS Press, 2012, p. 158-163.

14. Vincevica-Gaile, Z., Klavins, M., Zilgalve, L. Trace and Major Element Concentration in Cottage Cheese from Latvia. In: Mastorakis, N., Mladenov, V., Savkovic-Stevanovic, J. (eds.) Recent Researches in Sociology, Financing, Environment \& Health Sciences, WSEAS Press, 2011, p. 169-173.

15. Zegnere, L., Alsina, I. The Effect of Selenite on Growth and Storage of Onions. Latvian Journal of Agronomy, 2008, vol. 10, p. 235-240.

16. Vincevica-Gaile, Z., Klavins, M., Rudovica, V., et al. Trace and Major Elements in Food Articles in Latvia: Root Vegetables. Scientific Journa of Riga Technical University, Series: Environmental and Climate Technologies, 2011, vol. 13, N 7, p. 119-124.

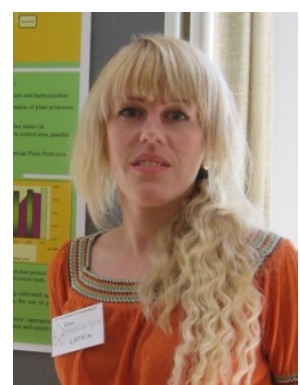

Zane Vincevica-Gaile, M. Sc., currently is a $\mathrm{PhD}$ candidate at the University of Latvia, Faculty of Geography and Earth Sciences, Department of Environmental Science. Z. Vincevica-Gaile has obtained Degree of Pharmacist at the Latvia Medical Academy in 2002 and Master Degree in Environmental Science at the University of Latvia in 2009. She is interested in research of trace and major element detection in food and interconnections between food composition and environmental factors, as well as possible element transfer routes into food chain with subsequent health effects. Z. Vincevica-Gaile is a member of the International Medical Geology Association.

Address: Alberta Street 10, Riga, LV-1010, Latvia

Phone: +371 26523248

E-mail: zane.gaile@lu.lv

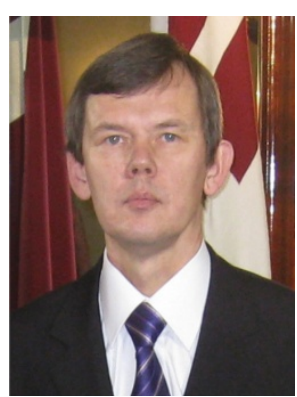

Maris Klavins, Dr. hab. chem., is professor at the University of Latvia, Faculty of Geography and Earth Sciences, Department of Environmental Science. M. Klavins obtained his scientific degree in chemistry of biologically active compounds at the Moscow State University in 1986, but a habilitation degree at the University of Latvia in 1994. He is a member of the Academy of Sciences of Latvia, coordinator of International Humic Substances Research Society (IHSS). Research interests are related to studies of natural organic matter, wetlands and bogs and environmental pollution

problems

Address: Alberta Street 10, Riga, LV-1010, Latvia

Phone: +371 67334096

E-mail: maris.klavins@lu.lv 